\title{
The Effect of Taxifolin on Acrylamide-induced Oxidative and Proinflammatory Brain Injury in Rats: A Biochemical and Histopathological Study
}

\author{
Alevtina Ersoy ${ }^{1, *}$, Hasan Yasar ${ }^{1}$, Ceyda Tanoglu', Gulce Naz Yazici², Taha Abdulkadir Coban ${ }^{3}$, \\ Yusuf Kemal Arslan ${ }^{4}$, Halis Suleyman ${ }^{5}$ \\ 1'Department of Neurology, Faculty of Medicine, Erzincan Binali Yildirim University, Erzincan, TURKEY. \\ ${ }^{2}$ Department of Histology, Faculty of Medicine, Erzincan Binali Yildirim University, Erzincan, TURKEY. \\ ${ }^{3}$ Department of Biochemistry, Faculty of Medicine, Erzincan Binali Yildirim University, Erzincan, TURKEY. \\ ${ }^{4}$ Department of Biostatistics, Faculty of Medicine, Erzincan Binali Yildirim University, Erzincan, TURKEY. \\ ${ }^{5}$ Department of Pharmacology, Faculty of Medicine, Erzincan Binali Yildirim University, Erzincan, TURKEY.
}

\begin{abstract}
Purpose: Acrylamide is a well-known environmental toxic compound. Taxifolin belongs to the group of flavonoids that have antioxidant, antimicrobial, anti-inflammatory and anticarcinogenic properties. In this study, we investigated the effect of taxifolin on acrylamiderelated oxidative and proinflammatory brain damage. Methods: The experimental animals were divided into three groups: (1) those treated with acrylamide $20 \mathrm{mg} / \mathrm{kg} \mathrm{p.o.,} \mathrm{(2)} \mathrm{those}$ treated with taxifolin $50 \mathrm{mg} / \mathrm{kg} \mathrm{p.o.} \mathrm{and} \mathrm{acrylamide} \mathrm{and} \mathrm{(3)} \mathrm{the} \mathrm{control} \mathrm{group.} \mathrm{At} \mathrm{the} \mathrm{end}$ of the experiment, the rat brain tissues were examined for the levels of Malondialdehyde (MDA), total glutathione (tGSH), tumor necrosis factor-alpha (TNF- $\alpha$ ) and interleukin-1 beta (IL-1 $\beta$ ). A histopathological analysis was performed to detect the morphological changes in the brain. Results: Exposure to acrylamide caused a significant increase in the levels of MDA, TNF- $\alpha$ and IL- $1 \beta$ and a decrease in the values of tGSH, which indicates the presence of oxidative stress and inflammation in the brain tissue. Taxifolin treatment significantly reduced the levels of MDA and TNF- $\alpha$ and brought the mean values of IL-1 $\beta$ and tGSH close to those of the control group. The group that received acrylamide exhibited histopathological changes, such as neuronal degeneration, edema of microglia, dilated and congestive vessels and apoptotic inclusion. The use of taxifolin significantly improved the morphological changes in the brain tissue of the acrylamideexposed rats. Conclusion: Acrylamide causes brain damage, inducing oxidative stress and inflammation. Due to its antioxidant and anti-inflammatory properties, taxifolin may be one of the agents that can reduce the neurotoxic effects of acrylamide.
\end{abstract}

Key words: Acrylamide, Brain damage, Inflammation, Neurotoxicity, Oxidative stress, Taxifolin.

\section{INTRODUCTION}

Acrylamide, as a chemical compound, was first discovered in 1893 by Christian Moureu in Germany. ${ }^{1}$ Acrylamide (ACR, $\mathrm{CH}_{2}=\mathrm{CHCONH}_{2}$ ) is colorless, odorless and highly water-soluble crystals. It is formed by the hydration of acrylonitrile with sulfuric acid monohydrate ${ }^{2}$ and used in many industries, including water treatment, cosmetic products and paper production, as well as in textile, mineral and concrete processing. ${ }^{1}$ Acrylamide is produced in high-carbohydrate and low-protein foods that undergo high-temperature processes, such as frying, baking, overcooking, or microwaving. ${ }^{3}$ The monomer form of acrylamide has been proven to be a strong toxin of the central and peripheral nervous systems in humans and animals. However, for the toxic damage of the central nervous system, higher doses of acrylamide are needed than required for the development of those in the peripheral nervous system., ${ }^{1,2}$
Submission Date: 20-11-2020;

Revision Date: 17-05-2021; Accepted Date: 23-09-2021

DOI: 10.5530/ijper.55.3s.183 Correspondence: Dr. Alevtina Ersoy, Erzincan Binali Yildirim University, Department of Neurology, Mengucek Gazi Training and Research Hospital, Erzincan, TURKEY. Phone: + 905332145569 Email - alevtina_ersoy@ hotmail.com

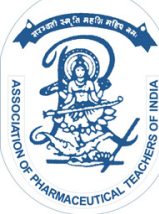

www.ijper.org 
It has been shown that acrylamide causes lipid peroxidation (LPO) and oxidative stress, leading to the overproduction of reactive oxygen species (ROS), which play a role in the pathogenesis of neurotoxicity. ${ }^{4}$ Recent studies showed that acrylamide caused oxidative brain damage by increasing Malondialdehyde (MDA) production in the brain tissue and reducing endogenous glutathione (GSH) concentrations as well as activities of antioxidant enzymes. ${ }^{5-8}$ Moreover, it has been demonstrated that acrylamide produced neurotoxic effects by increasing the production of both oxidants and proinflammatory cytokines such as interleukin-1 $\beta$ (IL-1 $\beta$ ), interleukin-6 (IL-6) and tumor necrosis factor-alpha (TNF- $\alpha$ ). ${ }^{6-9}$ These literature data suggest that antioxidant and anti-inflammatory drugs can be useful in the treatment of the neurotoxicity of acrylamide.

Flavonoids are a group of secondary metabolic compounds commonly found in plants as essential ingredients of human nutrition and have become very popular due to their multiple health-promoting and disease-preventing effects. ${ }^{10,11}$ Taxifolin (3,5,7,3,4-pentahydroxyflavanone or dihydroquercetin) is an antioxidant flavonoid that was first obtained from Douglas fir bark and Siberian larch. ${ }^{12}$ Studies have shown that taxifolin exerts various pharmacological effects, including antioxidant, antiinflammatory, antiviral, antibacterial, anticancer and neuroprotective activities. In addition, taxifolin has been found to inhibit the production of ROS. ${ }^{10,12,13}$ However, in the literature, no information has been found about the protective effects of taxifolin against brain damage caused by acrylamide. Therefore, the aim of our study was to perform a biochemical and histopathological evaluation of the effect of taxifolin on acrylamide-induced brain damage in rats.

\section{MATERIALS AND METHODS}

\section{Experimental animals}

The present study involved 18 albino Wistar male rats weighing $275 \mathrm{~g}$ to $286 \mathrm{~g}$. All experimental animals were taken from the Medical Experimental Application and Research Center of Ataturk University, Erzurum, Turkey. For adaptation to the new environment, one week before the experiment, the rats were kept at normal room temperature $\left(22^{\circ} \mathrm{C}\right)$ and fed rat chow and water ad libitum. The study protocol was approved by the Ethics Committee of Ataturk University, Erzurum, Turkey (Number: 244, Date: 26.12.2019). All the stages of the experiment were performed in accordance with the National Research Council of the National Academies Guide for the Care and Use of Laboratory Animals ethical rules.

\section{Chemicals}

Taxifolin was obtained from Evalar (Russia), acrylamide was obtained from Sigma-Aldrich Chemical Company (USA) and thiopental sodium was obtained from IE Ulagay (Turkey).

\section{Experimental groups}

All experimental animals were randomly divided into three groups: an acrylamide-treated group (ACR, $n=6$ ), a taxifolin + acrylamide-treated group (TACR, $n=6$ ) and the control group (CG, $n=6$ ) receiving distilled water.

\section{Experimental design}

Taxifolin was administered to the TACR group at a dose of $50 \mathrm{mg} / \mathrm{kg}$ orally by gavage into the stomach. Distilled water was administered orally to the ACR group and CG at the same volume as the vehicle. One hour after the treatment with taxifolin and distilled water, the TACR and ACR groups were orally given acrylamide at a dose of $20 \mathrm{mg} / \mathrm{kg}$ using the same method. This protocol was applied once a day for 30 days. At the end of experiment, the animals were killed with thiopental sodium at a dose of $50 \mathrm{mg} / \mathrm{kg}$ and the brain tissues were extracted. The removed brain tissues were examined with biochemical and histopathological methods. The results obtained from the TACR and ACR groups were compared with each other and with CG.

\section{Biochemical analysis \\ Preparation of samples}

For MDA determination in the brain tissue, we used $1.15 \%$ potassium chloride solution and for the other measurements, phosphate buffer at $\mathrm{pH}$ 7.5. The brain tissue was homogenized in ice and completed to $2 \mathrm{ml}$ with an appropriate solution. It was then centrifuged at $10,000 \mathrm{rpm}$ at $+4^{\circ} \mathrm{C}$ for $15 \mathrm{~min}$. The supernatant portion was used as the analysis sample.

\section{Malondialdehyde (MDA) analysis}

The MDA measurement was carried out according to the method identified by Ohkawa et al. ${ }^{14}$ This method is based on the spectrophotometric measurement of the absorbance of the pink-colored complex formed by MDA with high temperature $\left(95^{\circ} \mathrm{C}\right)$ thiobarbituric acid (TBA) at $532 \mathrm{~nm}$. After the homogenates were centrifuged at 5,000 g for $20 \mathrm{~min}$, the obtained supernatants were used to determine the MDA level. For this measurement, $250 \mu \mathrm{L}$ of homogenate was vortexed with $100 \mu \mathrm{L}$ of $8 \%$ sodium dodecyl sulfate, $750 \mu \mathrm{L}$ of $20 \%$ acetic acid, $750 \mu \mathrm{L}$ of $0.08 \%$ TBA and $150 \mu \mathrm{L}$ of pure 
water into capped test tubes. After the incubation of the mixture at $100^{\circ} \mathrm{C}$ for $60 \mathrm{~min}, 2.5 \mathrm{ml}$ of n-butanol was added for the spectrophotometric measurement. The saturation of the red color formed was defined using $3 \mathrm{ml}$ cuvettes at $532 \mathrm{~nm}$. The MDA level in the samples was measured using standard graphs created in advance from a stock of MDA solution prepared in accordance with the dilution coefficients.

\section{Total glutathione (tGSH) analysis}

The quantity of tGSH in the specimens was determined using a modified method of Sedlak and Lindsay. ${ }^{15}$ At first, the samples were weighed and homogenized in $2 \mathrm{~mL}$ of $50 \mathrm{mmol} / \mathrm{L}$ Tris- $\mathrm{HCl}$ buffer containing $20 \mathrm{mmol} / \mathrm{L}$ EDTA and $0.2 \mathrm{mmol} / \mathrm{L}$ sucrose at $\mathrm{pH} 7.5$. The homogenate was immediately precipitated with $0.1 \mathrm{~mL}$ of $25 \%$ trichloroacetic acid. After centrifugation at 4,200 rpm for $40 \mathrm{~min}$ at $4{ }^{\circ} \mathrm{C}$, the obtained precipitate was removed. The amount of tGSH was determined in the remaining supernatant. A total of $1,500 \mu \mathrm{L}$ of measurement buffer $(200 \mathrm{mmol} / \mathrm{L}$ Tris- $\mathrm{HCl}$ buffer containing $0.2 \mathrm{mmol} / \mathrm{L}$ EDTA at $\mathrm{pH} 7.5), 500 \mu \mathrm{L}$ supernatant, $100 \mu \mathrm{L}$ DTNB $(10 \mathrm{mmol} / \mathrm{L})$ and $7,900 \mu \mathrm{L}$ methanol were added to a tube and vortexed. After the incubation of the mixture for $30 \mathrm{~min}$ at $37^{\circ} \mathrm{C}$, we used 5,5-Dithiobis (2-nitrobenzoic acid) (DTNB), which formed a yellow-color complex with sulfhydryl groups as a chromogen. The absorbance was measured at $412 \mathrm{~nm}$ using a spectrophotometer (Beckman DU 500, USA). The reduced glutathione was used to determine the standard curve.

\section{IL-1 $\beta$ and TNF- $\alpha$ analysis in tissue}

Rat-specific sandwich enzyme-linked immunosorbent assay Rat Interleukin $1 \beta$ ELISA kit (Cat no:YHB0616Ra, Shanghai LZ) was used to determine the tissue-homogenate IL-1 $\beta$ quantity and Rat Tumor Necrosis Factor- $\alpha$ ELISA kit (Cat no: YHB1098Ra, Shanghai LZ) was used for measuring the tissue-homogenate TNF- $\alpha$ concentrations. All the measurements were carried out in accordance with the manufacturers' instructions. First, the monoclonal antibody specific to rat IL-1 $\beta$ and TNF- $\alpha$ were coated onto the microplates wells. Then, the tissue homogenate, standards and biotinylated monoclonal antibody specific and streptavidin-HRP were pipetted into these wells. After incubation at $37^{\circ} \mathrm{C}$ for $60 \mathrm{~min}$ and washing, the chromogen reagents $\mathrm{A}$ and $B$ were added, which produced color in the presence of bound enzymes. After the incubation of microplates at $37^{\circ} \mathrm{C}$ for $10 \mathrm{~min}$, the stop solution was added. The intensity of this colored product and the concentration of rat IL- $1 \beta$ and TNF- $\alpha$ present in the original samples were directly proportional. Finally, a microplate reader (Bio-Tek, USA) at $450 \mathrm{~nm}$ was used to estimate the well plates. The absorbance of the samples was evaluated with formulas using standard graphics.

\section{Histopathologic examination}

First, all the tissue samples were fixed in a 10\% formaldehyde solution for light microscope assessment. Then, the specimens were washed under tap water in cassettes for $24 \mathrm{hr}$. Following washing, the tissue samples were treated with alcohol in increasing concentrations $(70 \%$, $80 \%, 90 \%$ and $100 \%$ ) to remove the water within the tissues. Subsequently, the samples were passed through xylol and embedded in paraffin. Sections of paraffin blocks of 4-5 microns in thickness were stained with hematoxylin-eosin dye and photographed using an Olympus DP2-SAL firmware program (Olympus ${ }^{\circledR}$ Inc., Tokyo, Japan). The histopathological assessment of the slices was performed by a pathologist blinded to the study groups.

\section{Statistical Analysis}

Statistical analysis was performed using IBM SPSS v. 22 (IBM Corp. Released 2013. IBM SPSS Statistics for Windows, Version 22.0. Armonk, NY: IBM Corp.). For continuous variables, the results were reported as mean \pm standard deviation. The normality assumption for oxidant/antioxidant and proinflammatory markers was confirmed with the Kolmogorov-Smirnov test. The comparison of the groups was carried out using one-way analysis of variance (ANOVA). For all the variables, the homogeneity of variances assumption was analyzed by Levene's test. After ANOVA, Tukey's HSD was used as a post hoc test. A value of $p<0.05$ was accepted as statistically significant.

\section{RESULTS}

The results of the biochemical analysis of all groups are shown in Table 1 . There was a significant difference between the groups in terms of the MDA, tGSH, IL-1 $\beta$ and TNF- $\alpha$ levels ( $p<0.001$ for all).

To determine the difference between the two groups, binary comparisons were undertaken. The MDA levels were significantly higher in the ACR group compared to the control and TACR groups ( $p<0.001$ for both). However, there was no significant difference between the control and TACR groups $(p=0.456)$ (Figure 1). The tGSH levels were significantly lower in the ACR group compared to the control and TACR groups ( $p<0.001$ for both). Although the mean value of tGSH in the TACR group approached that of the CG, there 


\begin{tabular}{|c|c|c|c|c|}
\hline \multicolumn{2}{|c|}{ Table 1: Antioxidant/oxidant and proinflammatory levels of the study groups. } & \\
\hline & & Groups & TACR & p \\
\cline { 2 - 5 } & CG & ACR & $1.59 \pm 0.16$ & $<0.001$ \\
\hline MDA $(\mu \mathrm{mol} / \mathrm{gr}$ protein) & $1.39 \pm 0.37$ & $3.35 \pm 0.28$ & $3.85 \pm 0.11$ & $<0.001$ \\
\hline tGSH $(\mathrm{nmol} / \mathrm{gr}$ protein) & $4.49 \pm 0.27$ & $1.46 \pm 0.19$ & $2.92 \pm 0.15$ & $<0.001$ \\
\hline $\mathrm{IL}-1 \beta(\mathrm{pg} / \mathrm{ml})$ & $2.66 \pm 0.14$ & $5.75 \pm 0.15$ & $2.23 \pm 0.18$ & $<0.001$ \\
\hline TNF- $\alpha(\mathrm{pg} / \mathrm{ml})$ & $2.01 \pm 0.17$ & $4.99 \pm 0.14$ & & $<$ \\
\hline
\end{tabular}

The results are presented as mean \pm standard deviation (SD). CG - control group; ACR - acrylamide-treated group; TACR - taxifolin + acrylamide-treated group. MDA - malondialdehyde, tGSH - total glutathione, IL-1 $\beta$ - interleukin-1 beta, TNF- $\alpha$ - tumor necrosis factor-alpha.

was still a significant difference between these two groups $(p<0.001)$ (Figure 2).

The IL-1 $\beta$ levels were significantly higher in the ACR group compared to the control and TACR groups ( $p<0.001$ for both). However, despite the significant difference between the control and TACR groups $(p=0.024)$, their mean values were close to each other (Figure 3).

The TNF- $\alpha$ levels were significantly higher in the ACR group compared to the control and TACR groups ( $p<0.001$ for both). However, there was no significant difference between the control and TACR groups $(p=0.076)$ (Figure 4).

The histopathological findings of the groups are shown in Figure 5 (A-D). The sections of the cerebral cortex tissue in the CG demonstrated that the neurons, astrocytes, oligodendrocytes and microglia had a normal structure and distribution (Figure 5A). Morphological degeneration was observed in the neurons in the ACR group. In addition, the astrocytes were swollen and pericellular edema developed in oligodendrocytes. There was a significant increase in the population of microglia compared to the CG. The tissue blood vessels looked dilated and congested (Figure 5B). An examination of the sections of the same group at high resolution revealed apoptotic bodies in the nerve tissue (Figure 5C). In the TACR group, the neurons mostly exhibited a normal morphology. The astrocytes and oligodendrocytes had normal appearance and microglia had a normal distribution. No dilatation or congestion was detected in the blood vessels (Figure 5D).

\section{DISCUSSION}

Recently, attention has been drawn to the toxic effects of acrylamide on the central nervous system. In a rat study by Ultra et al. the acute oral lethal dose of acrylamide was determined as $114.81 \mathrm{mg} / \mathrm{kg} .{ }^{16}$ Moreover, acute exposure to acrylamide administered by intracerebroventricular route was found to cause dopaminergic

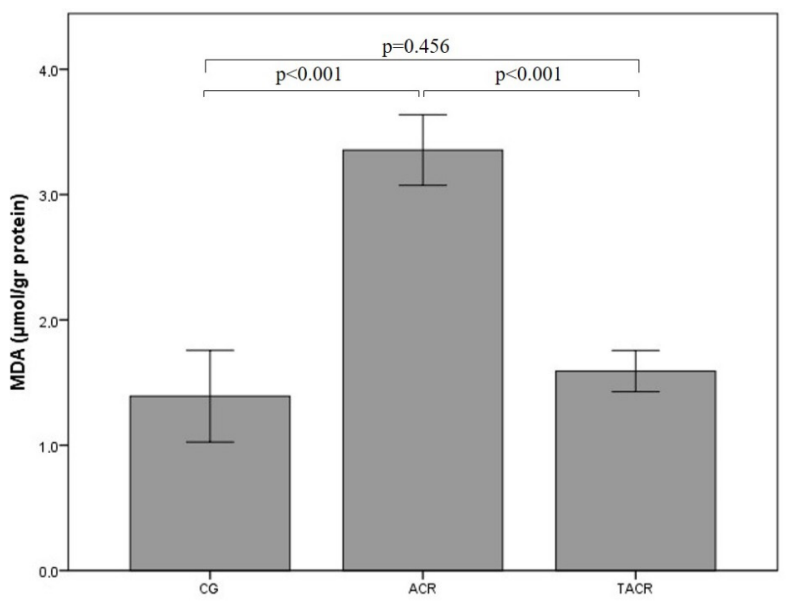

Figure 1: Comparison of the malondialdehyde (MDA) levels between the study groups. CG - control group; ACR - acrylamide-treated group; TACR - taxifolin + acrylamidetreated group.

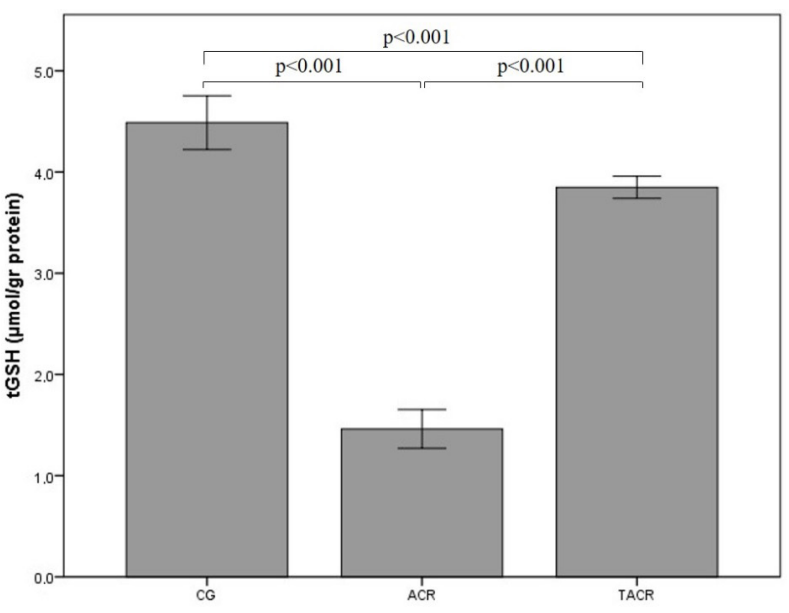

Figure 2: Comparison of the total glutathione (tGSH) levels between the study groups. CG - control group; ACR - acrylamide-treated group; TACR - taxifolin + acrylamidetreated group.

neuron loss. ${ }^{17}$ In the in vitro study of Park et al. a high dose of $50 \mathrm{mg} / \mathrm{kg}$ was shown to trigger the death of neural progenitor cells and to impair adult hippocampal neurogenesis by increased intracellular ROS levels. ${ }^{18}$ 


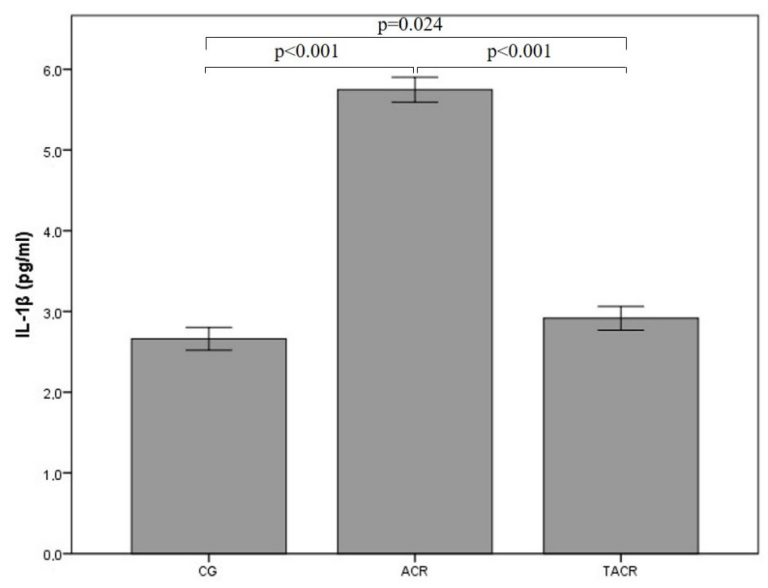

Figure 3: Comparison of the interleukin-1 beta (IL-1 $\beta$ ) levels between the study groups. CG - control group; ACR - acrylamide-treated group; TACR - taxifolin + acrylamidetreated group.

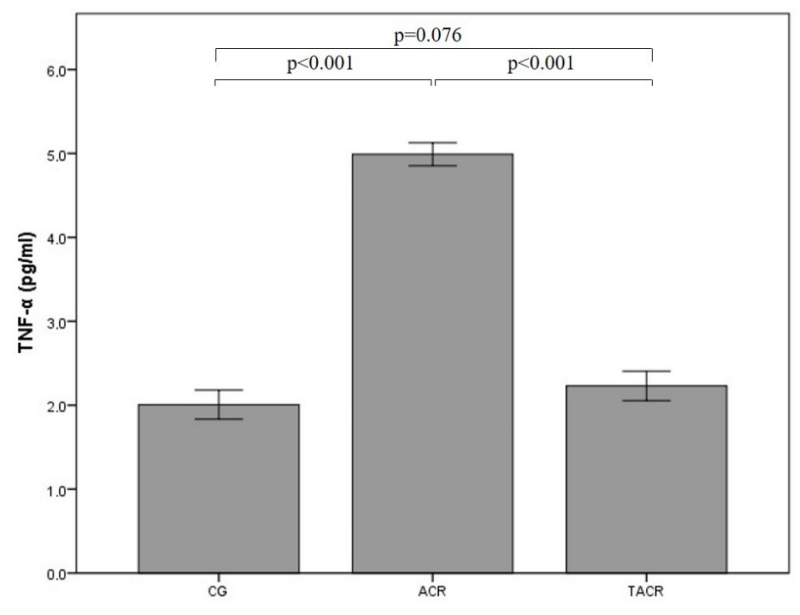

Figure 4: Comparison of the tumor necrosis factor-alpha (TNF- $\alpha$ ) levels between the study groups. CG - control group; ACR - acrylamide-treated group; TACR - taxifolin + acrylamide-treated group.

As in environmental exposures, the subchronic acrylamide treatment of mice at lower doses ( $\max 200 \mu \mathrm{g} / \mathrm{kg}$ ) did not significantly alter the numbers of newly generated cells in the hippocampus but affected their spatial learning and memory. ${ }^{19}$ Cognitive, exploratory and motor impairment due to acrylamide exposure was also observed in other studies. ${ }^{9,20}$ Another sign of acrylamide-induced central nervous system damage is ataxia. Studies showed dose-dependent worsening in the gait, unsteady walking pattern, reduced tail-flick time, abnormal posture of the feet and legs, foot-dragging and weakness of forelimbs. ${ }^{21-24}$ LoPachin et al. reported the damage of Purkinje cells in the cerebellum, as well as neurodegeneration in all cerebrum areas, which could possibly cause of ataxia. ${ }^{25}$

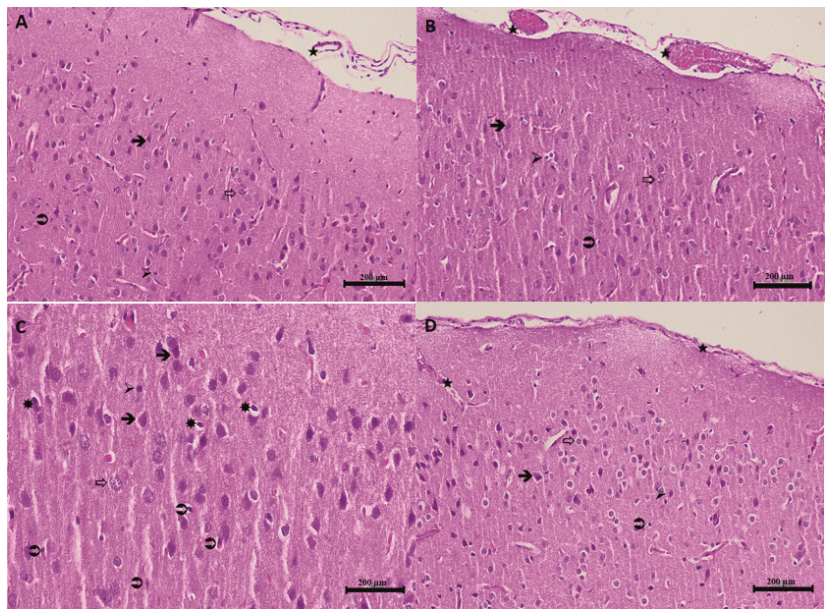

Figure 5: Histopathological features of the brain tissue. A - Hematoxylin-eosin staining of the cerebral cortex in the control group (CG): $\rightarrow$ : neurons, $\Rightarrow$ : astrocytes, $>$ : oligodendrocytes, $\Rightarrow$ : microglia, $\ni$ : blood vessels, x200; B-C - Hematoxylin-eosin staining of the cerebral cortex in the acrylamidetreated (ACR) group: $\rightarrow$ : degenerated neurons, $\Rightarrow$ : swollen astrocytes, $>$ : oligodendrocytes with pericellular edema, $\vartheta$ : increased microglia, $\star$ : dilated and congested blood vessels, x200, : apoptotic bodies, x400; D - Hematoxylin-eosin staining of the cerebral cortex in the acrylamide + taxifolin-treated (TACR) group: $\rightarrow:$ neurons, $\Rightarrow$ : astrocytes, $>$ : oligodendrocytes, : : microglia, $\star$ : blood vessels, $\mathbf{x} 200$.

Acrylamide directly targets nerve terminals causing synaptic dysfunction via neurotransmitter release impairment. As a result, acrylamide intoxication manifests with central/peripheral distal axonopathy. ${ }^{26}$ The neurotoxicity of acrylamide also affects serotonergic, ${ }^{27}$ dopaminergic ${ }^{4,23,27}$ and cholinergic ${ }^{16,21,28}$ pathways.

One of the factors taking part in the development of the toxic effect of acrylamide is oxidative stress, ${ }^{29}$ which results from an imbalance in the oxidative/antioxidative system and can lead to neuron death, as well as neuronal dysfunction. ${ }^{30}$ In animal studies, acrylamide has been shown to increase oxidative damage markers in the brain and serum such as MDA, , $^{6-9,17,21,22} 8$-hydroxydeoxyguanosine (8-OHdG), ${ }^{6-8,27} \mathrm{TBA}$ index ${ }^{16}$ and nitric oxide, ${ }^{6-9}$ indicating intracerebral lipid peroxidation. Similarly, in our study, the MDA levels in the brain of the ACR group were found higher than those of the rats that did not receive acrylamide. Moreover, the tGSH levels, which is a non-enzymatic antioxidant, were low, indicating insufficient antioxidative capacity. Other papers also support this finding. In several studies, the rat brain tissue exposed to acrylamide exhibited a decrease in the levels of reduced glutathione (GSH) $)^{6-9,16,17,21,22,31}$ and enzymatic antioxidants, such as superoxide dismutase, $(6-9,16)$ catalase, $(6-9,16)$ glutathione peroxidase, ${ }^{6-9,21,31}$ glutathione S-transferase, ${ }^{21}$ and glutathione reductase. ${ }^{21}$ These data suggest that 
oxidative stress is involved in acrylamide-related central neurotoxicity.

Yan $e t$ al. found that acrylamide caused an increase in nuclear factor kappa B (NF-kB) activity in the brain tissue. ${ }^{17} \mathrm{NF}-\kappa \mathrm{B}$ is an oxidative stress-responsive transcription factor that activates the transcription of genes regulating the inflammatory and immune response. ${ }^{32}$ This indicates a link between oxidative stress and inflammation. As seen in previous studies, acrylamide exposure induces an inflammatory response by the release of various cytokines. ${ }^{6-8,17,27,33}$ In the present study, the TNF- $\alpha$ and IL-1 $\beta$ levels were found high in rat brains exposed to acrylamide. The same cytokines were found to be high in the acrylamide-treated rat brains in a study by Goudarzi et al. ${ }^{9}$ This suggests that inflammation may play a role in the development of acrylamide-induced brain damage.

Since the neurotoxicity of acrylamide may be associated with oxidative stress and inflammation, many antioxidants, including those that are plant-based have been investigated for their protective effects on the central nervous system..$^{6-9,16,22,27,33}$ In the present study, we evaluated the possible antioxidant and anti-inflammatory properties of taxifolin on acrylamide-induced brain injury. Previous animal studies have shown the antioxidant effects of taxifolin in reducing LPO and xanthine oxidase activity, ${ }^{34,35}$ as well as stimulating antioxidant heme-oxygenase -1 and $\mathrm{NAD}(\mathrm{P}) \mathrm{H}$ quinone oxidoreductase - 1 gene expression through the Nrf2-depending pathway. ${ }^{36}$ Maksimovich et al. showed that in a cerebral ischemia/reperfusion model, taxifolin decreased the levels of MDA, pyruvate and lactate and increased the GSH levels, thereby reducing oxidative stress. ${ }^{31}$ Similarly, in our study, taxifolin improved the acrylamide-induced cerebral oxidant/ antioxidant balance by increasing tGSH and decreasing MDA. However, the fact that despite the increase in the tGSH levels, they were not as high as those of the control group, can be explained through the excessive depletion of tGSH due to the ability of acrylamide and its metabolite, glycidamide, to directly connect with glutathione sulfhydryl (-SH) groups. ${ }^{1}$

A rat model with cerebral ischemia/reperfusion showed that taxifolin suppressed the release of ROS and nitric oxide in leukocyte and microglia cells and also inhibited proinflammatory parameters, such as leukocyte infiltration into the brain and activities of cyclooxygenase - 2 , inducible nitric oxide synthase and NF- $\kappa B .{ }^{37}$ In the present study, anti-inflammatory effect of taxifolin on acrylamide-induced cerebral injury was confirmed by the decrease in TNF- $\alpha$ and IL-1 $\beta$ in the TACR group compared to the CG. Our data also support the conclusions of Ahiskali et al. who demonstrated that the TNF- $\alpha$ and IL-1 $\beta$ levels were significantly lower in the group given taxifolin in alloxan-induced diabetic rats compared to the group that did not receive this drug. ${ }^{38}$ Similarly, in a methanol-induced optic neurite study, it was found that taxifolin reduced the release of NF- $\kappa$ B and TNF- $\alpha .{ }^{39}$ After evaluating all the data, we concluded that taxifolin had an antioxidant and antiinflammatory effect on the brain damage induced by acrylamide.

In the course of the histopathological examination, we found that the toxic effect of acrylamide led to an increase in the population and edema of microglia, degenerative changes in neurons, vasodilation and vascular congestion and formation of apoptotic inclusions in the brain tissue. This is in line with the findings indicating acrylamide-related neuron necrosis, such as dark neurons, ${ }^{22}$ condensed nuclei and eosinophilic cytoplasm in neuron and glial cells. ${ }^{9}$ Other animal studies investigating the neurotoxic effects of acrylamide also found glial edema and blood-brain barrier damage, as well as synapse loss. ${ }^{24}$ Our data for the group receiving taxifolin and acrylamide showed that the morphology of the neurons was mostly improved and the microglia and blood vessels had normal appearance. Very few studies carried out a histopathological examination of the neuroprotective effect of taxifolin. Dajas et al. found that taxifolin did not significantly increase the survival of PC 12 cells after treating the culture of these cells with a solution of hydrogen peroxide and taxifolin. ${ }^{40}$ On the contrary, Nakusov et al. noted that with the development of acute hypoxia, treatment with dihydroquercetin suppressed LPO and thereby prevented the occurrence of morphological changes in many organs, including the brain, which is in line with our results. ${ }^{41}$

\section{CONCLUSION}

In the present preliminary study examining the rat brain with biochemical and histopathological methods, we found that acrylamide exposure caused cerebral injury by increasing oxidant and proinflammatory markers and decreasing antioxidant content. The administration of taxifolin not only reduced acrylamide-induced brain damage by suppressing oxidative stress and inflammation, but also improved the histopathological changes in the brain tissue. We suggest that taxifolin may be useful in treating acrylamide-induced central neurotoxicity, but more research is needed to confirm this. 


\section{ACKNOWLEDGEMENT}

We thank Christine Margaret Calvert for language proofreading of this manuscript.

\section{CONFLICT OF INTEREST}

The authors declare that they have no conflict of interest.

\section{ABBREVIATIONS}

ACR: Acrylamide; EDTA: Ethylenediaminetetraacetic acid; GSH: reduced glutathione; tGSH: total glutathione; IL-13: interleukin-1 beta; IL-6: interleukin-6; LPO: lipid peroxidation; MDA: malondialdehyde; NF- $\varkappa$ B: nuclear factor kappa B; Nrf2: nuclear factor erythroid 2-related factor 2; ROS: reactive oxygen species; TBA: thiobarbituric acid; TNF- $\alpha$ : tumor necrosis factoralpha: 8-OHdG: 8-hydroxydeoxyguanosine.

\section{REFERENCES}

1. Smith EA, Oehme FW. Acrylamide and polyacrylamide: a review of production, use, environmental fate and neurotoxicity. Rev Environ Health. 1991;9(4):215-28. doi: 10.1515/reveh.1991.9.4.215, PMID 1668792.

2. Friedman M. Chemistry, biochemistry, and safety of acrylamide. A review. J Agric Food Chem. 2003;51(16):4504-26. doi: 10.1021/jf030204+, PMID 14705871.

3. Lingnert H, Grivas S, Jägerstad M, Skog K, Törnqvist M, Åman P. Acrylamide in food: mechanisms of formation and influencing factors during heating of foods. Scand J Nutr. 2002;46(4):159-72. doi: 10.1080/110264802762225273.

4. LoPachin RM, Barber DS, Gavin T. Molecular mechanisms of the conjugated alpha,beta-unsaturated carbonyl derivatives: relevance to neurotoxicity and neurodegenerative diseases. Toxicol Sci. 2008;104(2):235-49. doi: 10.1093/ toxsci/kfm301, PMID 18083715.

5. Tabeshpour J, Mehri S, Abnous K, Hosseinzadeh H. Role of oxidative stress, MAPKinase and apoptosis pathways in the protective effects of thymoquinone against acrylamide-induced central nervous system toxicity in rat. Neurochem Res. 2020;45(2):254-67. doi: 10.1007/s11064-019-02908-z, PMID 31728856.

6. Elhelaly AE, AlBasher G, Alfarraj S, Almeer R, Bahbah El, Fouda MMA, Bungău SG, Aleya L, Abdel-Daim MM. Protective effects of hesperidin and diosmin against acrylamide-induced liver, kidney, and brain oxidative damage in rats. Environ Sci Pollut Res Int. 2019;26(34):35151-62. doi: 10.1007/s11356-019-06660-3, PMID 31686333.

7. Abdel-Daim MM, Abd Eldaim MA, Hassan AG. Trigonella foenumGraecum ameliorates acrylamide-induced toxicity in rats: Roles of oxidative stress, proinflammatory cytokines, and DNA damage. Biochem Cell Biol. 2015;93(3):192-8. doi: 10.1139/bcb-2014-0122, PMID 25607344.

8. Abdel-Daim MM, Abo El-Ela FI, Alshahrani FK, Bin-Jumah M, Al-Zharani M, Almutairi B, Alyousif MS, Bungau S, Aleya L, Alkahtani S. Protective effects of thymoquinone against acrylamide-induced liver, kidney and brain oxidative damage in rats. Environ Sci Pollut Res Int. 2020;27(30):37709-17. doi: 10.1007/s11356-020-09516-3, PMID 32608003.

9. Goudarzi M, Mombeini MA, Fatemi I, Aminzadeh A, Kalantari H, Nesari A, Najafzadehvarzi $\mathrm{H}$, Mehrzadi S. Neuroprotective effects of ellagic acid against acrylamide-induced neurotoxicity in rats. Neurol Res. 2019;41(5):419-28. doi: 10.1080/01616412.2019.1576319, PMID 30735102.

10. Rice-Evans CA, Miller NJ, Paganga G. Structure-antioxidant activity relationships of flavonoids and phenolic acids. Free Radic Biol Med. 1996;20(7):933-56. doi: 10.1016/0891-5849(95)02227-9, PMID 8743980.

11. Salaritabar A, Darvishi B, Hadjiakhoondi F, Manayi A, Sureda A, Nabavi SF, Fitzpatrick LR, Nabavi SM, Bishayee A. Therapeutic potential of flavonoids in inflammatory bowel disease: A comprehensive review. World J Gastroenterol. 2017;23(28):5097-114. doi: 10.3748/wjg.v23.i28.5097, PMID 28811706.

12. Sunil $\mathrm{C}, \mathrm{Xu}$ B. An insight into the health-promoting effects of taxifolin (dihydroquercetin). Phytochemistry. 2019;166:112066. doi: 10.1016/j. phytochem.2019.112066.

13. Cai C, Liu C, Zhao L, Liu H, Li W, Guan H, Zhao L, Xiao J. Effects of taxifolin on osteoclastogenesis in vitro and in vivo. Front Pharmacol. 2018;9:1286. doi: 10.3389/fphar.2018.01286, PMID 30483128.

14. Ohkawa H, Ohishi N, Yagi K. Assay for lipid peroxides in animal tissues by thiobarbituric acid reaction. Anal Biochem. 1979;95(2):351-8. doi: 10.1016/0003-2697(79)90738-3, PMID 36810.

15. Sedlak J, Lindsay RH. Estimation of total, protein-bound, and nonprotein sulfhydryl groups in tissue with Ellman's reagent. Anal Biochem. 1968;25(1):192-205. doi: 10.1016/0003-2697(68)90092-4, PMID 4973948.

16. Uthra C, Shrivastava S, Jaswal A, Sinha N, Reshi MS, Shukla S. Therapeutic potential of quercetin against acrylamide induced toxicity in rats. Biomed Pharmacother. 2017;86:705-14. doi: 10.1016/j.biopha.2016.12.065, PMID 28039850.

17. Yan D, Pan X, Yao J, Wang D, Wu X, Chen X, Shi N, Yan H. MAPKs and NF-KB-mediated acrylamide-induced neuropathy in rat striatum and human neuroblastoma cells SY5Y. J Cell Biochem. 2019;120(3):3898-910. doi: 10.1002/jcb.27671, PMID 30368882.

18. Park HR, Kim MS, Kim SJ, Park M, Kong KH, Kim HS, Kwack SJ, Kang TS, Kim SH, Kim HS, Lee J. Acrylamide induces cell death in neural progenitor cells and impairs hippocampal neurogenesis. Toxicol Lett. 2010;193(1):86-93. doi: 10.1016/j.toxlet.2009.12.015, PMID 20035847.

19. Lee S, Park HR, Lee JY, Cho JH, Song HM, Kim AH, Lee W, Lee Y, Chang SC, Kim HS, Lee J. Learning, memory deficits, and impaired neuronal maturation attributed to acrylamide. J Toxicol Environ Health A. 2018;81(9):254-65. doi: 10.1080/15287394.2018.1440184, PMID 29473799.

20. Yan D, Yao J, Liu Y, Zhang X, Wang Y, Chen X, Liu L, Shi N, Yan H. Tau hyperphosphorylation and $\mathrm{P}-\mathrm{CREB}$ reduction are involved in acrylamideinduced spatial memory impairment: suppression by curcumin. Brain Behav Immun. 2018;71:66-80. doi: 10.1016/j.bbi.2018.04.014, PMID 29704550.

21. Lebda MA, Gad SB, Rashed RR. The effect of lipoic acid on acrylamideinduced neuropathy in rats with reference to biochemical, hematological, and behavioral alterations. Pharm Biol. 2015;53(8):1207-13. doi: 10.3109/13880209.2014.970288, PMID 25853975

22. Mehri S, Abnous K, Khooei A, Mousavi SH, Shariaty VM, Hosseinzadeh H. Crocin reduced acrylamide-induced neurotoxicity in Wistar rat through inhibition of oxidative stress. Iran J Basic Med Sci. 2015;18(9):902-8. PMID 26523222.

23. Pan X, Guo X, Xiong F, Cheng G, Lu Q, Yan H. Acrylamide increases dopamine levels by affecting dopamine transport and metabolism related genes in the striatal dopaminergic system. Toxicol Lett. 2015;236(1):60-8. doi: 10.1016/j.toxlet.2015.04.017, PMID 25943760.

24. Zhang B, Shao H, Wang XH, Chen X, Li ZS, Cao P, Zhu D, Yang YG, Xiao JW, Li B. Acrylamide-induced subacute neurotoxic effects on the cerebral cortex and cerebellum at the synapse level in rats. Biomed Environ Sci. 2017;30(6):432-43. doi: 10.3967/bes2017.057, PMID 28705267.

25. LoPachin RM, Balaban CD, Ross JF. Acrylamide axonopathy revisited. Toxicol Appl Pharmacol. 2003;188(3):135-53. doi: 10.1016/s0041-008x(02)00072-8, PMID 12729714.

26. LoPachin RM. The changing view of acrylamide neurotoxicity. Neurotoxicology. 2004;25(4):617-30. doi: 10.1016/j.neuro.2004.01.004, PMID 15183015.

27. Zargar S, Siddiqi NJ, Ansar S, Alsulaimani MS, El Ansary AK. Therapeutic role of quercetin on oxidative damage induced by acrylamide in rat brain. Pharm Biol. 2016;54(9):1763-7. doi: 10.3109/13880209.2015.1127977, PMID 26730789.

28. Kopanska M, Muchacka R, Czech J, Batoryna M, Formicki G. Acrylamide toxicity and cholinergic nervous system. J Physiol Pharmacol. 2018;69(6). doi: 10.26402/jpp.2018.6.03, PMID 30898983.

29. Yousef $\mathrm{MI}$, El-Demerdash FM. Acrylamide-induced oxidative stress and biochemical perturbations in rats. Toxicology. 2006;219(1-3):133-41. doi: 10.1016/j.tox.2005.11.008, PMID 16343728.

30. Dasuri K, Zhang L, Keller JN. Oxidative stress, neurodegeneration, and the balance of protein degradation and protein synthesis. Free Radic Biol 
Med. 2013;62:170-85. doi: 10.1016/j.freeradbiomed.2012.09.016, PMID 23000246.

31. Maksimovich NY, Dremza IK, Troian El, Maksimovich YN, Borodinskiĭ AN. [The correcting effects of dihydroquercetin in cerebral ischemia-reperfusion injury]. Biomed Khim. 2014;60(6):643-50. doi: 10.18097/pbmc20146006643, PMID 25552503.

32. Baeuerle PA, Henkel T. Function and activation of NF-kappa B in the immune system. Annu Rev Immunol. 1994;12:141-79. doi: 10.1146/annurev. iy.12.040194.001041, PMID 8011280.

33. Zhang L, Wang E, Chen F, Yan H, Yuan Y. Potential protective effects of oral administration of allicin on acrylamide-induced toxicity in male mice. Food Funct. 2013;4(8):1229-36. doi: 10.1039/c3fo60057b, PMID 23760623.

34. Akinmoladun AC, Oladejo CO, Josiah SS, Famusiwa CD, Ojo OB, Olaleye MT. Catechin, quercetin and taxifolin improve redox and biochemical imbalances in rotenone-induced hepatocellular dysfunction: relevance for therapy in pesticide-induced liver toxicity? Pathophysiology: the official journal of the International Society for Pathophysiology. 2018;25(4):365-71.

35. Teselkin YO, Babenkova IV, Kolhir VK, Baginskaya AI, Tjukavkina NA, Kolesnik YA, Selivanova IA, Eichholz AA. Dihydroquercetin as a means of antioxidative defence in rats with tetrachloromethane hepatitis. Phytother Res. 2000;14(3):160-2. doi: 10.1002/(sici)1099-1573(200005)14:3<160::aidptr555>3.0.co;2-y, PMID 10815007.

36. Liang L, Gao C, Luo M, Wang W, Zhao C, Zu Y, Efferth T, Fu Y. Dihydroquercetin (DHQ) induced $\mathrm{HO}-1$ and $\mathrm{NQO} 1$ expression against oxidative stress through the Nrf2-dependent antioxidant pathway. J Agric Food Chem. 2013;61(11):2755-61. doi: 10.1021/jf304768p, PMID 23419114.

37. Wang YH, Wang WY, Chang CC, Liou KT, Sung YJ, Liao JF, Chen CF, Chang S, Hou YC, Chou YC, Shen YC. Taxifolin ameliorates cerebral ischemiareperfusion injury in rats through its anti-oxidative effect and modulation of NF-kappa B activation. J Biomed Sci. 2006;13(1):127-41. doi: 10.1007/ s11373-005-9031-0, PMID 16283433.

38. Ahiskali I, Pinar CL, Kiki M, Mammadov R, Ozbek Bilgin A, Hacimuftuoglu A, Cankaya M, Keskin Cimen F, Altuner D. Effect of taxifolin on development of retinopathy in alloxan-induced diabetic rats. Cutan Ocul Toxicol. 2019;38(3):227-32. doi: 10.1080/15569527.2019.1588289, PMID 30897968.

39. Ahiskali I, Pinar CL, Kiki M, Cankaya M, Kunak CS, Altuner D. Effect of taxifolin on methanol-induced oxidative and inflammatory optic nerve damage in rats. Cutan Ocul Toxicol. 2019;38(4):384-9. doi: 10.1080/15569527.2019.1637348, PMID 31242797.

40. Dajas F, Rivera F, Blasina F, Arredondo F, Echeverry C, Lafon L, Morquio A, Heinzen $\mathrm{H}$. Cell culture protection and in vivo neuroprotective capacity of flavonoids. Neurotox Res. 2003;5(6):425-32. doi: 10.1007/BF03033172, PMID 14715446.

41. Nakusov TT, Shortanova TKh, Kon' Ila, Samoilik NI, Kubardiev MM. [The influence of antioxidants on morphological structure of internal organs of rats in acute hypoxia]. Vopr pitan. 2005;74(5):22-3. PMID 16313132.

\section{PICTORIAL ABSTRACT}

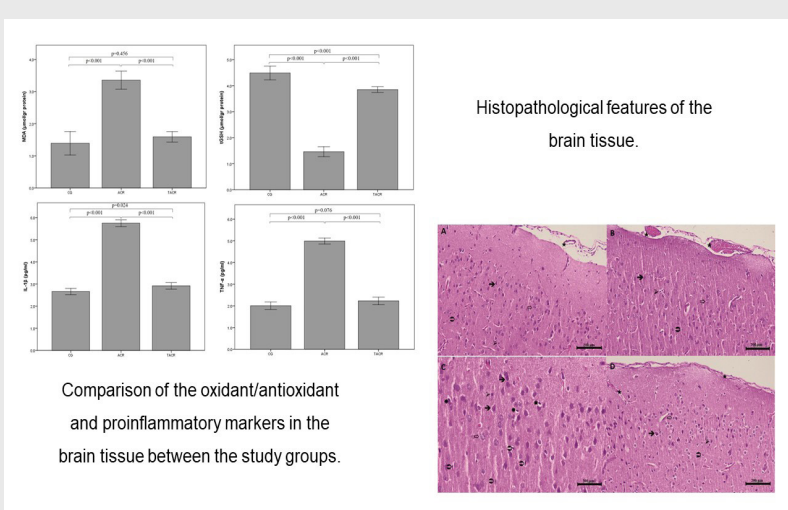

\section{SUMMARY}

- Acrylamide exposure leads to the oxidative and proinflammatory brain damage.

- Acrylamide causes degeneration of the neurons and edema of the microglia.

- Taxifolin improves oxidant/antioxidant balance in the acrylamide-damaged brain.

- Taxifolin reduces the acrylamide-associated increase of the proinflammatory markers.

- Taxifolin repairs the acrylamide-induced morphological changes in the brain tissue.

\section{About Authors}

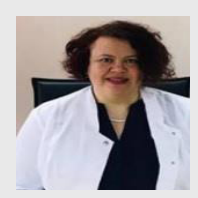

Dr. Alevtina Ersoy is working at Erzincan Binali Yildirim University as Assistant Professor at the Department of Neurology. At the same time, she works at the Mengücek Gazi Research and Training Hospital, which is affiliated with this university. Dr. Alevtina Ersoy was awarded the "Doctor of the Year" by Health Ministry in March 2016. Her fields of interest are neurotoxicology, neuroimmunology and epilepsy.

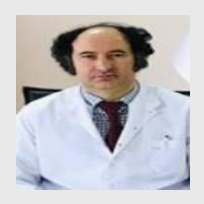

Dr. Hasan Yasar completed his neurology residency in Van Yuzuncu Yıl University. He is working at the Neurology Department of Erzincan Binali Yidirim University for 5 years. He is interested in demyelinating and neurodegenerative diseases.

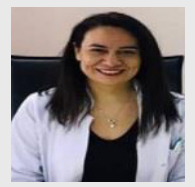

Dr. Ceyda Tanoglu graduated from Ege University Faculty of Medcine in 2000 and completed her neurology residency in Ankara Baskent University hospital. She is working at Erzincan Binali Yildirim University as Assistant Profesor at the Department of Neurology. Her fields of interest are neurotoxicology, movement disorders and stroke. 

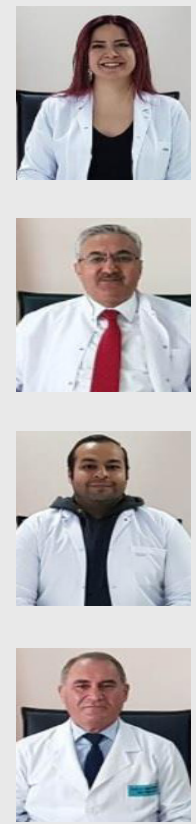

Dr. Gulce Naz Yazici has obtained her PhD degree from Gazi University School of Medicine, Department of Histology and Embryology. She completed her post-doctorals research in Center for Human and Environmental Toxicology in the College of Veterinary Medicine at the University of Florida. Her area of interest is in toxicology and histopathology. She has authored more than 20 research papers in international journals.

Dr. T. Abdulkadir Coban received his doctorate degree from Ataturk University, Institute of Science, Department of Biochemistry. He completed his postdoctoral research at the Ohio State University Biotechnology Center. His area of interest is protein production by enzymes and cloning. He has written more than 35 research articles in international journals.

Dr. Yusuf Kemal Arslan is working as Asst. Prof. in the Department of Biostatistics at the Medical Faculty of Erzincan Binali Yildirim University. He has completed his BSc in Statistics from Ege University, MSc in Biostatistics from Cukurova University Institute of Health Sciences and PhD in Biostatistics from Ankara University Institute of Health Sciences. His field of interest is Biostatistics and Epidemiology.

Dr. Halis Suleyman is working as Professor in the Medical Pharmacology Department at Erzincan Binali Yildirim University. He has a total teaching and research experience of 25 years. Dr. Halis Süleyman is the owner of many awards and patents, and he has more than 300 publications in prestigious national and international journals. His major research interests is pain, inflammation, canser and experimental stomach ulcers.

Cite this article: Ersoy A, Yasar H, Tanoglu C, Yazici GN, Coban TA, Arslan YK, Suleyman H. The Effect of Taxifolin on Acrylamide-induced Oxidative and Proinflammatory Brain Injury in Rats: A Biochemical and Histopathological Study. Indian J of Pharmaceutical Education and Research. 2021;55(3s):s765-s773. 